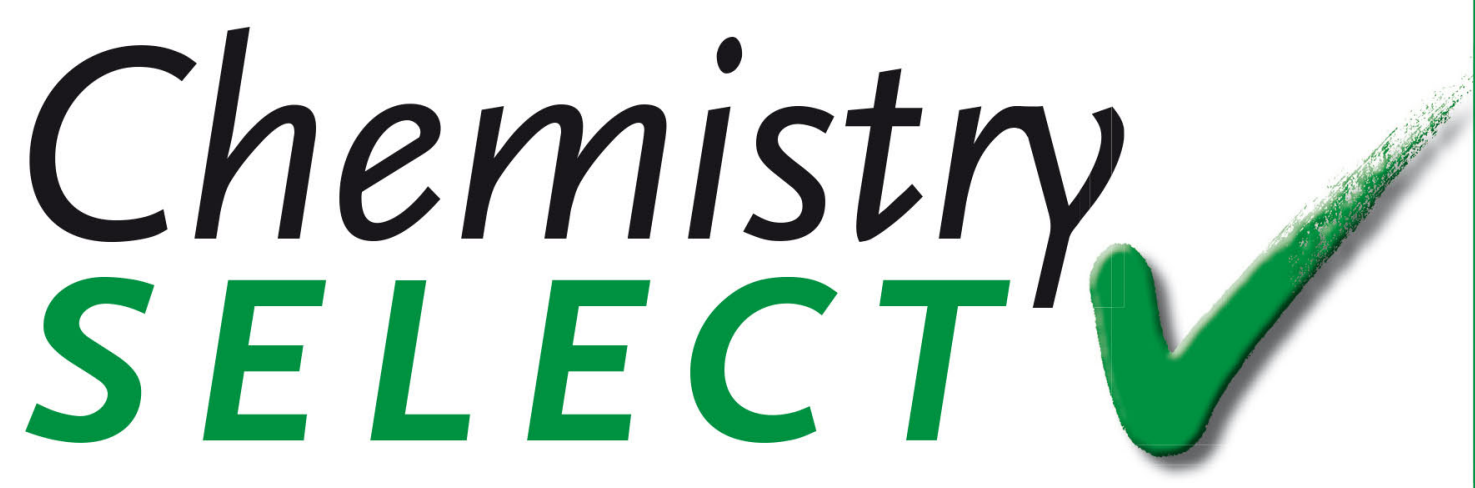

A journal of

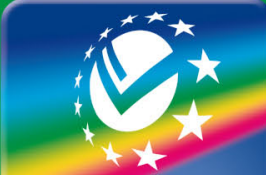

ChemPubSoc Europe

www.chemistryselect.org

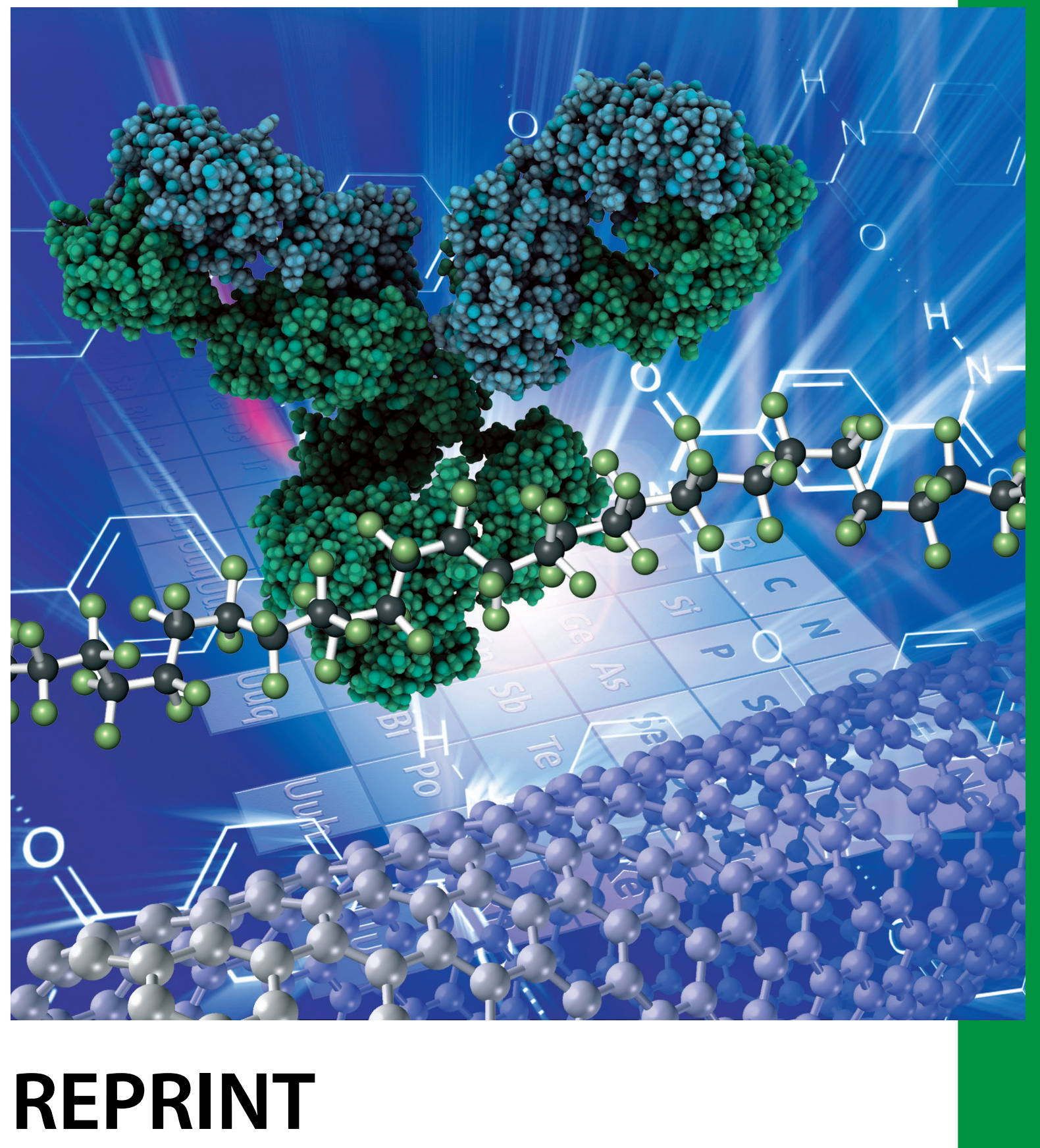

WILEY-VCH 


\title{
Stereoselective Synthesis of Chiral Isatin Containing Bisphosphonates as Potential Anti-Resorption Bone Drugs
}

\author{
Lorena De Luca, Andrea Chiminazzo, Laura Sperni, Giorgio Strukul, and Alessandro Scarso*[a]
}

Bisphosphonates are currently the major class of drugs used for the treatment of osteoporosis, a disease that leads to bone fragility and increase in fracture risk that affects hundreds of million elderly individual worldwide. All commercially available bisphosphonates are achiral albeit their activity is demonstrated to be related to inactivation of specific enzymes. Cinchona alkaloid urea derivatives are efficient organocatalysts

\section{Introduction}

Similarly to hydroxyapatite (HAP) that represents the major constituent of the mineral portion of bones, bisphosphonates (BP) are a class of molecules bearing two phosphonate moieties but connected through a methylene linker. BP are specific bone targeting species $^{[1]}$ used for decades in medicinal chemistry ${ }^{[2]}$ for the treatment of bone disorders such as hypocalcaemia and osteoporosis even though the correlation between their chemical structure and biological activity is still a highly debated topic. ${ }^{[3,4]}$ The cellular activity of BPs is related to their ability to inhibit specific enzymes like farnesyl diphosphate synthase (FPPS), geranylgeranyl diphosphate synthase $(G G P P S)^{[5,6]}$ and other ones ${ }^{[7]}$ present in osteoclasts that are the cells deputed for bone resorption.

The presence of an hydroxyl group in position $\mathrm{R}^{1}$ of the $\mathrm{BP}$ (Figure 1) provides higher affinity for HAP and the presence of $\mathrm{N}$ containing residues on $\mathrm{R}^{2}$ promotes a good performance in terms of anti-resorptive efficiency as in the commercially available alendronic and zoledronic acids clinically used to contrast osteoporosis (Figure 1). Further studies evidenced that more lipophilic BPs lacking the presence of the gem-OH group in position $\mathrm{R}^{1}$ and bearing $\mathrm{N}$ containing cationic residues with a long alkyl chain on $\mathrm{R}^{2}$ are even more efficient to contrast bone resorption ${ }^{[5]}$ with other therapeutic positive effects as anticancer $^{[8]}$ anti-bacterial and anti-malarial species. ${ }^{[9]}$ The search for more potent and better tolerated $\mathrm{N}$ containing BPs is a highly desirable topic. Similarly, the development of chiral BPs

[a] L. De Luca, Dr. A. Chiminazzo, L. Sperni, Prof. G. Strukul, Prof. A. Scarso Dipartimento di Scienze Molecolari e Nanosistemi

Università Ca' Foscari di Venezia

via Torino 155, 30172, Mestre (Ve), Italy

Tel: + 39-041-234-8569

Fax: + 39-041-234-8517

E-mail: alesca@unive.it

Supporting information for this article is available on the WWW under http://dx.doi.org/10.1002/slct.201700649 for the asymmetric aldol reaction of ketones to an isatin containing bisphosphonate precursor to provide a class of new chiral enantioenriched potentially anti-resorption bone drugs. High chemical yields were generally achieved in a wide array of substrates tested and in several cases ee's in the $60-96 \%$ range could be observed.

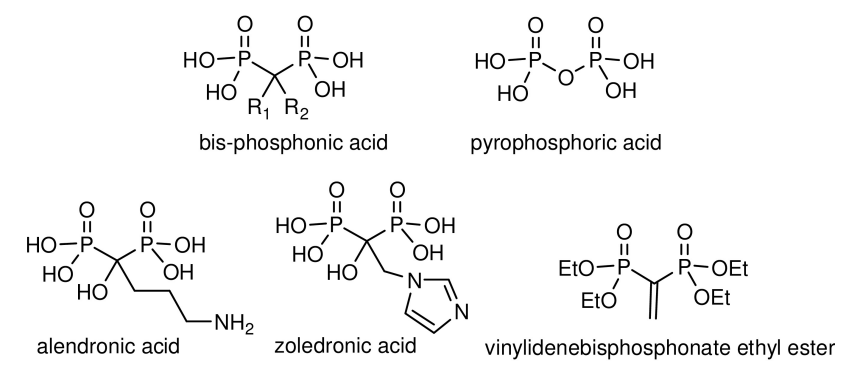

Figure 1. Chemical structure of bisphosphonates, pyrophosphoric acid, alendronic and zoledronic acids and vinylidenebisphosphonate tetraethyl ester.

and their investigation is a rather unexplored topic ${ }^{[10]}$ that deserve further investigation. ${ }^{[1]}$

BPs with $\mathrm{R}^{1}=\mathrm{OH}$ are usually prepared from a carboxylic acid $^{[12,13]}$ or an acyl chloride ${ }^{[14]}$ while BPs with $\mathrm{R}^{1}=\mathrm{H}$ are more commonly prepared by Michael addition of nucleophiles to vinylidenebisphosphonate tetraethylester $(\mathrm{VBP})^{[15]}$ as a typical building block. The latter approach enabled the preparation of several classes of BPs bearing steroid conjugates, ${ }^{[16]}$ heterocycles $^{[17]}$ or thiols. ${ }^{[18]}$ General classes of BPs have been prepared also by metal catalyzed addition of boronic acids and indoles to VBP as recently disclosed by our group. ${ }^{[19,20]}$ VBP can be efficiently exploited as dienophile ${ }^{[21]}$ for cycloaddition reactions reacting with dienes ${ }^{[22]}$ and nitrones. ${ }^{[23]}$

Isatin is a simple molecule found both in plants ${ }^{[24]}$ and in the human body as it is a metabolic derivative of adrenaline ${ }^{[25]}$ but it is commonly employed also for the manufacture of dyes, pigments, flavors, pharmaceuticals, flame-proofing agents, corrosion inhibitors, dry bleaches, disinfectants, and sanitizing agents. It is a highly versatile starting material for the synthesis of natural products, heterocyclic, and non-cyclic compounds. ${ }^{[26]}$ This molecule and its derivatives showed a broad spectrum of biological activities ${ }^{[27]}$ like anti-HIV ${ }^{[28]}$ anti-bacterial, ${ }^{[29]}$ antifungal, ${ }^{[30]}$ anti-viral, ${ }^{[31]}$ properties to name a few. 
Asymmetric catalysis on Isatin ${ }^{[32]}$ derivatives has recently received great attention because it allows a series of highly enantioselective reactions, ${ }^{[33]}$ also for the preparation of biologically active spirooxindoles. ${ }^{[34]}$ In particular aldol reactions ${ }^{[35]}$ on isatin derivatives turned out to be extremely stereoselective when using amine based organocatalysts like chiral proline derivatives, ${ }^{[36]}$ 1,2-cyclohexanediamine species, ${ }^{[37]}$ leucinol and valinol as primary amines ${ }^{[38]}$ or Cinchona alkaloid amine derivatives. ${ }^{[39]}$ Alternatively, good stereoselectivities were observed also with a chiral thiourea catalyst bearing Cinchona units $^{[40]}$ or [2.2] paracyclophane-based derivatives. ${ }^{[4]]}$

In the present contribution we report the highly stereoselective synthesis of isatin containing BPs obtained by organocatalyzed aldol condensation on an isatin containing BP precursor (Scheme 1) as potential drug molecules to contrast
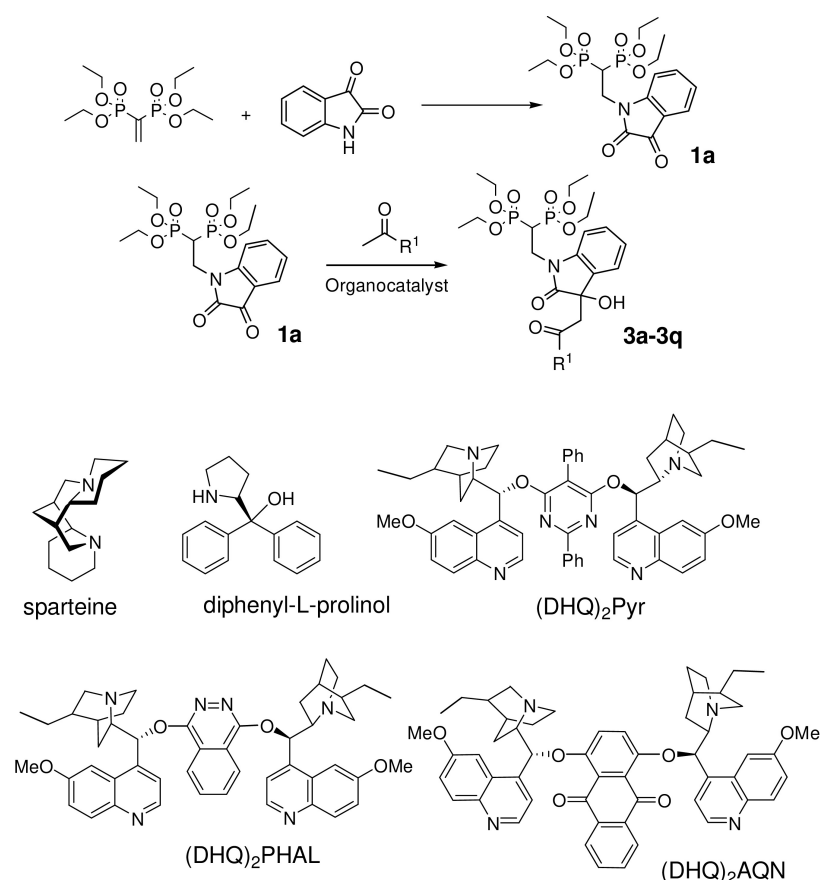

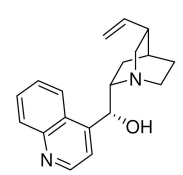

Cinchonidine
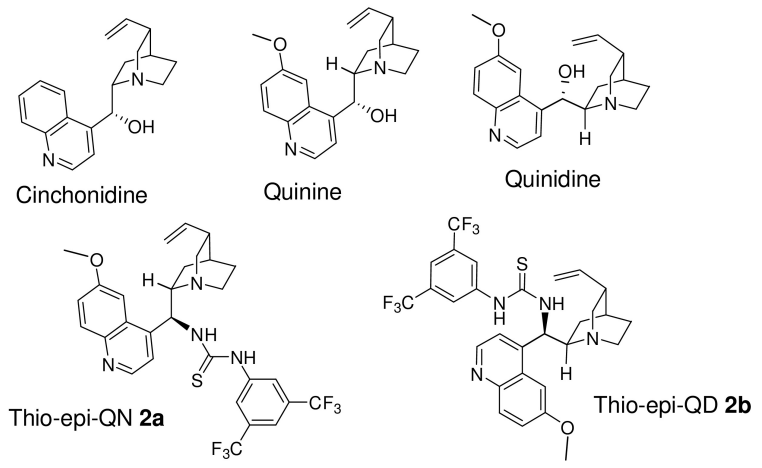

Scheme 1. Synthesis of tetraethyl [2-(2,3-dioxo-2,3-dihydro-1H-indol-1-yl) ethane-1,1-diyl]bis(phosphonate) $\mathbf{1}$ a by Michael addition of Isatin to VBP and organocatalyzed aldol condensation of carbonyl compounds to 1 a.

osteoporosis mediated by Cinchona alkaloid urea derivatives as efficient organocatalysts.

\section{Results and Discussion}

Since Isatin is a nucleophilic amide derivative already investigated for Michael reactions, ${ }^{[42]}$ the reaction between isatin and vinylidenebisphosphonate tetraethyl ester (VBP) was initially tested observing the formation of the corresponding tetraethyl product $1 \mathrm{a}$ as Michael addition BP product in $86 \%$ isolated yield after $18 \mathrm{~h}$ at $60^{\circ} \mathrm{C}$ (Scheme 1).

While Michael addition to VBP proceeded with excellent yields, attempts of isatin addition to monosubstituted VBP precursors led to their decomposition probably because of limited stability under basic condition. $\mathbf{1}$ a was subjected to subsequent deprotection of the phosphonate ester moiety by treatment with bromotrimethylsilane followed by hydrolysis with the water/methanol solution (9:1) to give the corresponding bisphosphonic acids $\mathbf{1} \mathbf{a}-\mathrm{OH}$ in good yield that is soluble in water and represents a model for the new class of chiral enantioenriched drug candidates.

$1 \mathrm{a}$ and $1 \mathrm{a}-\mathrm{OH}$ were characterized by ${ }^{1} \mathrm{H}$ and ${ }^{31} \mathrm{P}-\mathrm{NMR}$ spectroscopy in $\mathrm{CDCl}_{3}$ and $\mathrm{D}_{2} \mathrm{O}$ respectively showing in the latter case sharp signals indicative of the absence of aggregation phenomena in water (see Supporting Info). The carbonyl group in position 3 of the isatin moiety is an important electrophilic unit that can be further functionalized. The aldol condensation between acetone used as solvent and $\mathbf{1}$ a (Scheme 1) leading to the corresponding chiral tertiary alcohol was investigated using a series of organocatalysts in order to optimize the yield and stereoselectivity of the reaction. As reported in Table 1, the reaction with sparteine was completely

\begin{tabular}{|cccc|}
\hline \multicolumn{4}{|c|}{ Table 1. Synthesis of chiral aldol products between acetone and 1 a } \\
catalyzed by different organocatalysts.
\end{tabular}

inefficient, while using diphenyl-L-prolinol the expected product was formed in $85 \%$ yield after $48 \mathrm{~h}$ at room temperature, but unfortunately in the racemic form. We then tested a series of dimeric conjugates of cinchona alkaloids as reported in Table 1, entries 3-5, observing in all cases yields from 9 to $50 \%$ yield but with no or minimal asymmetric induction on the products. Among other alkaloids, cinchonidine led to the formation of the product in $51 \%$ yield and $10 \%$ ee, while higher yields were observed with quinine and quinidine $(63 \%$ 
and $75 \%$, respectively) still with low enantioselectivity (12 and $3 \%$ ee, respectively). The use of thiourea derivatives of epiquinine (Thio-epi-QN, 2a) and epi-quinidine (Thio-epi-QD, $\mathbf{2} \mathbf{b})^{[43]}$ allowed to improve the catalytic activity yielding better product formation ( 85 and $82 \%$ yield, respectively) in $18 \mathrm{~h}$ at room temperature, while an increase in asymmetric induction (34\% ee) was observed only with $\mathbf{2}$ b.

These results spurred the investigation of the solvent effect on the reaction. We repeated the aldol condensation between the isatin-BP adduct and 10 equivalents of acetone catalyzed by $\mathbf{2} \mathbf{b}$ in solvents like toluene, THF and acetonitrile observing after $48 \mathrm{~h}$ comparable yields in the condensation product (18, 21 and $32 \%$, respectively) but positively increased enantioselectivity (3, 23 and $48 \%$ ee, respectively). We also investigated the reaction with epi-quinidine-thiourea organocatalyst at $-10{ }^{\circ} \mathrm{C}$ instead of room temperature observing a decrease in product yield down to $35 \%$ but without increase in the stereoselectivity of the reaction, observing $36 \%$ ee similarly to room temperature.

In order to investigate the scope of the reaction, isatin-BP was reacted with different aliphatic and aromatic, cyclic and acyclic ketones in the presence of the aromatic thiourea derivatives $\mathbf{2} \mathbf{a}$ and $\mathbf{2} \mathbf{b}$ (Table 2 ). The ketones were used also as solvents when liquid at room temperature, while they were employed as $1.8 \mathrm{M}$ solution in acetonitrile if solid at room temperature. The isolated products were characterized by ${ }^{1} \mathrm{H}$, ${ }^{31} \mathrm{P},{ }^{13} \mathrm{C}$ NMR spectroscopy (see Supporting Info).

They are all characterized by two distinct resonances for the diastereotopic $\mathrm{P}$ atoms in the ${ }^{31} \mathrm{P}\left\{{ }^{1} \mathrm{H}\right\}-\mathrm{NMR}$ spectrum while ${ }^{1} \mathrm{H}$ NMR spectra showed typical signals ${ }^{[44]}$ assigned to $H_{a}$ (5.75 ppm) and to $H_{b}$ and $H_{c}$ (the overlapped signal at $3.25 \mathrm{ppm})$, as shown in the typical example reported in Figure 2.

The use of a longer aliphatic ketone like 2-octanone led with $\mathbf{2} \mathbf{b}$ to a similar yield compared to acetone but with a decrease in enantioselectivity down to $16 \%$ ee (Table 2, entry 2 ) while the sterically hindered 3,3,-dimethyl-2-butanone with the same organocatalyst did not form the expected aldol product (entry 3).

Cyclic aliphatic ketones showed very different results depending on the size of the ring. In fact, while cyclopentanone and cyclooctanone did not react with $\mathbf{2}$ b, cyclobutanone and cyclohexanone led to $79 \%$ and $>98 \%$ yield, respectively observing the formation of two diastereoisomeric species syn and anti.

While with the cyclobutanone derivative the separation of the stereoisomers and the determination of de and ee resulted impossible, with cyclohexanone using $\mathbf{2} \mathbf{b}$ as catalyst a diastereoisomeric ratio of $67: 33$ and $90 \%$ ee and $82 \%$ ee for the two pairs of enantiomers were observed (Table 2, entry 5). The same reaction carried out with 2 a provided $71 \%$ yield with $69: 31$ diastereoisomeric ratio and $62 \%$ ee and $91 \%$ ee for the pairs of enantiomers (Table 2, entry 5). It is worth noting that even though Quinine and Quinidine derivatives are true diastereoisomers differing for the inverted configuration at C8 and C9, often in asymmetric catalysis they behave as enantiomers leading to inversion of the stereoselectivity and because of this

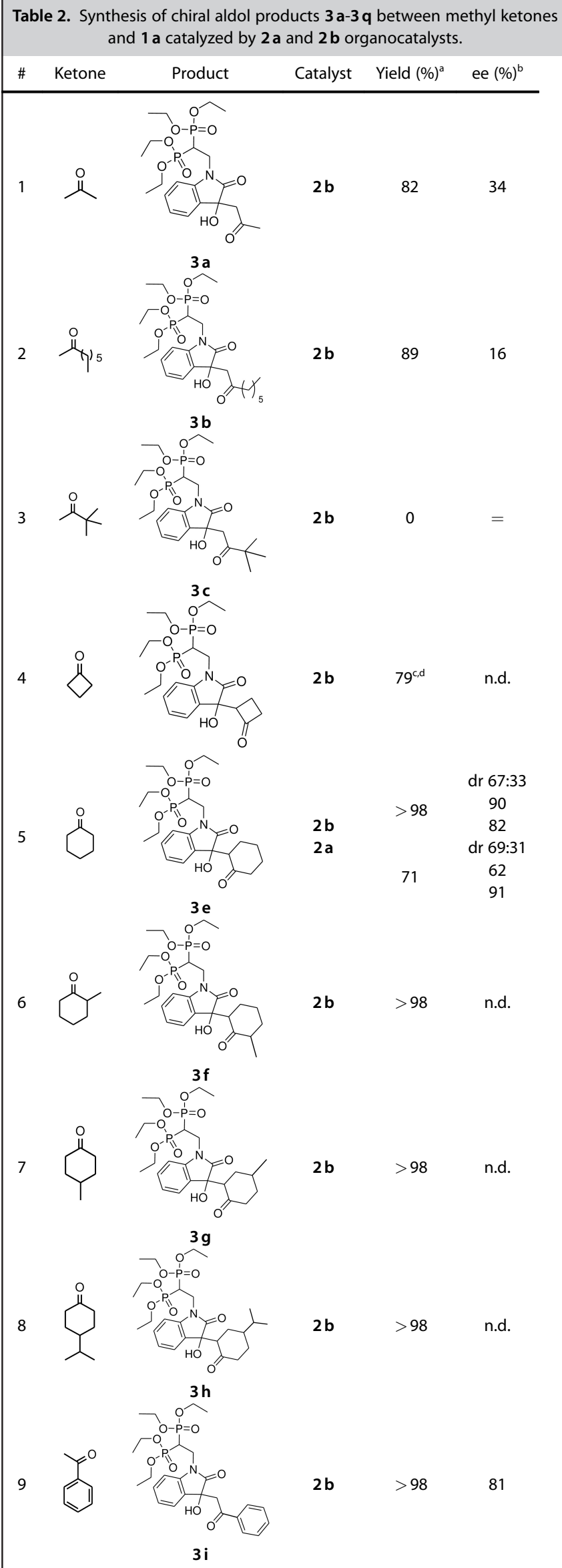




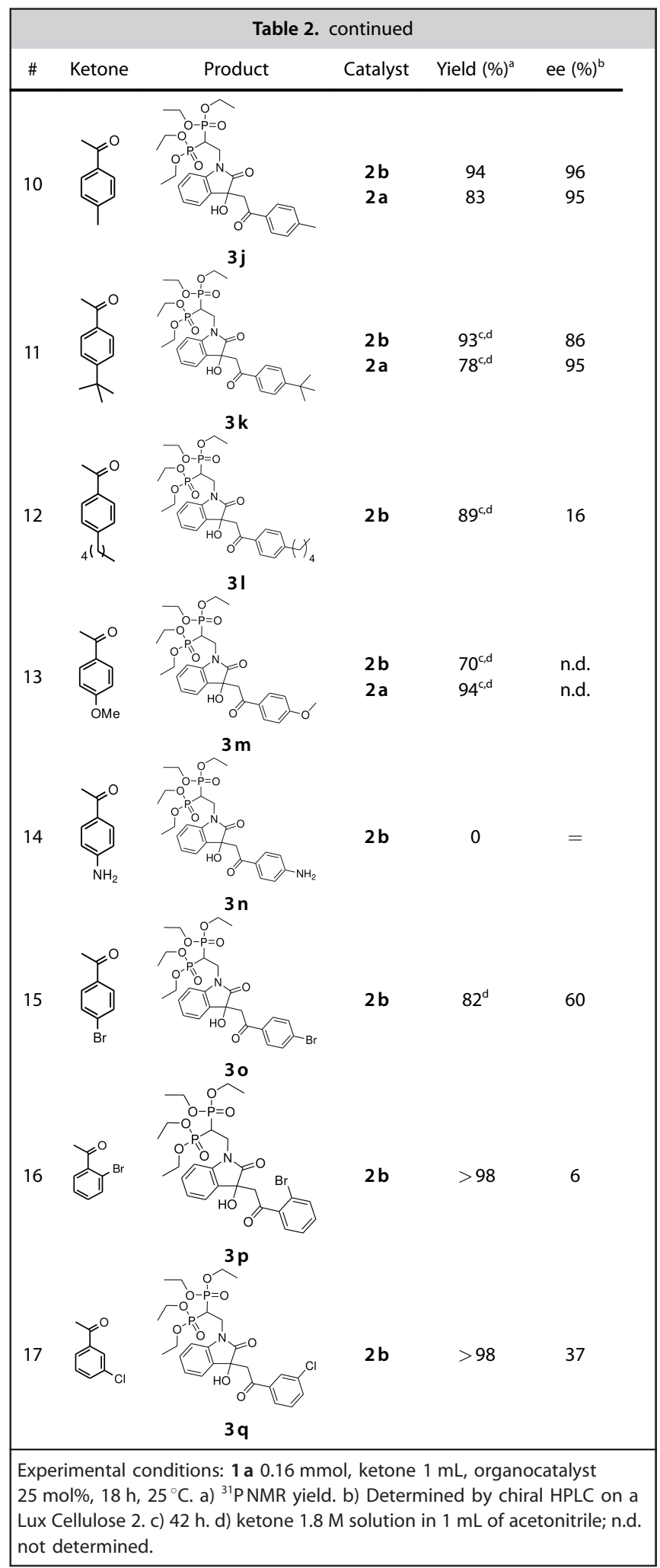

they are usually referred as pseudo-enantiomers. ${ }^{[45]}$ In the reactions reported in Table 2 this is specifically what was observed with cyclohexanone and other ketones. In fact, the two diastereoisomeric thiourea catalysts in most cases led to the formation of the corresponding aldol products in compara-

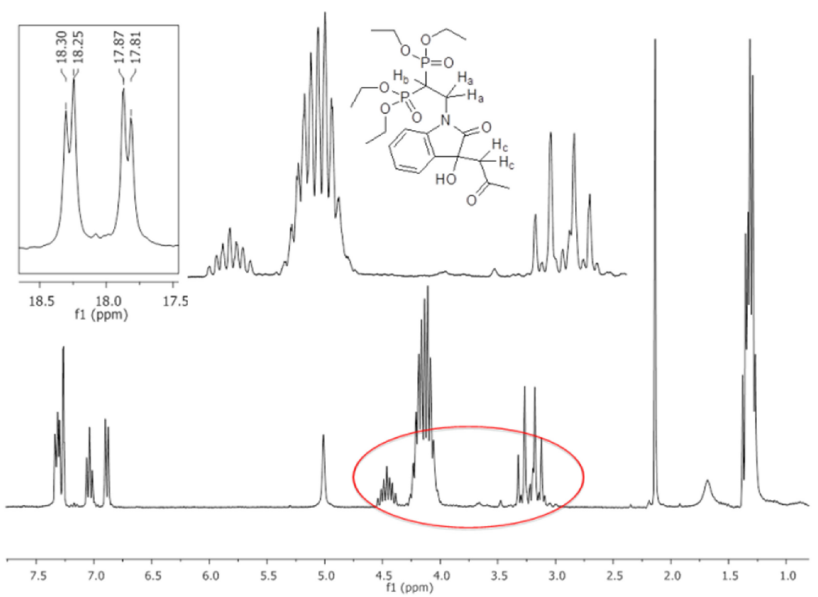

Figure 2. ${ }^{1} \mathrm{H}-\mathrm{NMR}$ and ${ }^{31} \mathrm{P}\left\{{ }^{1} \mathrm{H}\right\}-\mathrm{NMR}$ spectra of the addition product between $1 \mathrm{a}$ and acetone..

ble yields but with opposite enantioselectivities. Other cyclohexanones bearing 2- and 4-methyl or 4-isopropyl substituents on the six membered ring with $\mathbf{2} \mathbf{b}$ led to quantitative formation of the aldol condensation products but the presence of three stereocenters on the molecule led to a mixture of stereoisomers that could not be separated (Table 2, entries 68).

The reaction was extended to the use of aromatic ketones. In particular with $\mathbf{2} \mathbf{b}$ acetophenone led to quantitative formation of the desired product with $81 \%$ ee. We then investigated the steric and electronic effects of the acetophenone derivative on the stereoselective aldol condensation. This is the case of the reaction with $p$-methyl-acetophenone mediated by $\mathbf{2} \mathbf{b}$ that provided $94 \%$ yield with $96 \%$ ee in favor of the more retained enantiomer, while with $2 \mathrm{a}$ the yield was $83 \%$ and $95 \%$ ee in favor of the least retained enantiomer. With p-t-Bu-acetophenone yield was $93 \%$ with $86 \%$ ee for the most retained enantiomer when using $\mathbf{2} \mathbf{b}$, and the stereoselectivity was inverted with $\mathbf{2}$ a observing $78 \%$ yield with $95 \%$ ee for the least retained enantiomer. With $p$-pentyl-acetophenone using $\mathbf{2}$ b $89 \%$ yield was observed but with a marked decrease of enantioselectivity down to $16 \%$ ee. With electron donating groups like for $\mathrm{p}$-methoxy-acetophenone the reaction was efficient with $70 \%$ and $94 \%$ yield with $\mathbf{2}$ a and $\mathbf{2}$ b respectively, but the determination of the products ee by chiral HPLC resulted impossible. With electron withdrawing groups like $p$-bromo-acetophenone yield was $82 \%$ and $60 \%$ ee, while o-bromo-acetophenone led to quantitative product formation but a dramatic drop in ee $(6 \%)$. Similarly, $m$-chloro-acetophenone provided quantitative yield and $37 \%$ ee.

A plausible mechanism ${ }^{[46]}$ of the asymmetric organocatalyzed reaction is reported in the supporting information comprising the activation of the carbonyl groups of isatin by hydrogen bonding with the thiourea moiety and the concomitant methyl ketone deprotonation by the tertiary amine of the organocatalyst. 


\section{Conclusions}

In conclusion, herein we reported about the enantioselective organocatalyzed synthesis of isatin containing bisphosphonates as chiral potential anti-resorption bone drugs. The use of thiourea derived epi-Quinine and epi-Quinidine as organocatalysts enabled the efficient aldol condensation between carbonyl compounds such as acyclic and cyclic aromatic and aliphatic ketones to an isatin containing Michael addition product of VBP. In particular high yields were obtained with aliphatic acyclic and cyclic ketones with good level of enantioselectivity when using cyclohexanone. Alternatively, good yields and ee values up to $96 \%$ were observed with acetophenone derivatives. In most cases the alternative use of the two thiourea organocatalysts allowed to obtain predominantly either enantiomer of the aldol reaction products. Molecules $\mathbf{3} \mathbf{j}$ as major enantiomers are currently under study in order to investigate their biological and toxicological properties in the inhibition of bone resorption by osteoclasts and results will be reported soon.

\section{Supporting information summary}

The supporting information file contains experimental details about the organocatalytic stereoselective reactions for the formation of the aldol products, and full characterization of the products.

\section{Acknowledgements}

The authors acknowledge Università C $\mathrm{C}^{\prime}$ Foscari Venezia and MIUR for support.

\section{Conflict of Interest}

The authors declare no conflict of interest.

Keywords: aldol condensation - bisphosphonates - Cinchona alkaloids $\cdot$ isatin $\cdot$ organocatalysis

[1] S. Zhang, G. Gangal, H. Uludağ, Chem. Soc. Rev. 2007, 36, 507-531.

[2] R. Graham, G. Russell, Bone 2011, 49, 2-19.

[3] F. H. Ebetino, A.-M. L. Hogan, S. Sun, M. K. Tsoumpra, X. Duan, J. T. Triffitt, A. A. Kwaasi, J. E. Dunford, B. L. Barnett, U. Oppermann, M. W. Lundy, A. Boyde, B. A. Kashemirov, C. E. McKenna, R. G. G. Russell, Bone 2011, 49, 20-33.

[4] M. J. Rogers, J. C. Crockett, F. P. Coxon, J. Mönkkönen, Bone 2011, 49, 3441.

[5] Y. Zhang, R. Cao, F. Yin, M. P. Hudock, R.-T. Guo, K. Krysiak, S. Mukherjee, Y.-G. Gao, H. Robinson, Y. Song, J. H. No, K. Bergan, A. Leon, L. Cass, A. Goddard, T.-K. Chang, F.-Y. Lin, E. Van Beek, S. Papapoulos, A. H.-J. Wang, T. Kubo, M Ochi, D. Mukkamala, E. Oldfield, J. Am. Chem. Soc. 2009, 131, 5153-5162.

[6] A. J. Wiemer, J. S. Yu, L. W. Shull, R. J. Barney, B. M. Wasko, K. M. Lamb, R. J. Hohl, D. F. Wiemer, Bioorg. Med. Chem. 2008, 16, 3652-3660.

[7] A. G. Roth, D. Drescher, Y. Yang, S. Redmer, S. Uhlig, C. Arenz, Angew. Chem. Int. Ed. 2009, 48, 7560-7563.

[8] Y. Zhang, R. Cao, F. Yin, F.-Y. Lin, H. Wang, K. Krysiak, J.-H. No, D. Mukkamala, K. Houlihan, J. Li, C. T. Morita, E. Oldfield, Angew. Chem. Int. Ed. 2010, 49, 1136-1138.
[9] J.H. No, F. de Macedo Dossin, Y. Zhang, Y.-L. Liu, W. Zhu, X. Feng, J. Anny Yoo, E. Lee, K. Wang, R. Hui, L. H. Freitas-Junior, E. Oldfield, Proc. Natl. Acad. Sci. USA, 2012, 109, 4058-4063.

[10] a) M. Capuzzi, D. Perdicchia, K. A. Jørgensen, Chem. Eur. J. 2008, 14, 128135 ; b) S. Sulzer-Mossè, M. Tissot, A. Alexakis, Org. Lett. 2007, 9, 37493752; c) M. T. Barros, A. M. Faisca Philllips, Eur. J. Org. Chem. 2008, 25252529; d) M.-X. Zhao, T.-L. Dai, R. Liu, D.-K. Wei, H. Zhou, F.-H. Jia, M. Shi, Org. Biomol. Chem. 2012, 10, 7970-7979; e) A. M. Faísca Phillips, M. T. Barros, Org. Biomol. Chem. 2012, 10, 404-412, f) M. Dzięgielewski, J. Hejmanowska, Ł. Albrecht, Synthesis 2014, 46, 3233-3238.

[11] F. H. Ebetino, J. E. Dunford, M. W. Lundy, M. Pozzi, Z. Xia, R. Dobson, M. Quijano, R. Christian, B. A. Kashemirov, C. E. McKenna, G. G. Russell, B. L. Barnett, Bone 2008, 42, S36-S37.

[12] G. R. Kieczykowski, R. B. Jobson, D. G. Mellilo, D. F. Reinhold, V. J. Grenda, I. Shinkai, J. Org. Chem. 1995, 60, 8310-8312.

[13] M. Egorov, S. Aoun, M. Padrines, F. Redini, D. Heymann, J. Lebreton, M. Mathé-Allainmat, Eur. J. Org. Chem. 2011, 7148-7154.

[14] R. L. McConnell, H. W. Coower, J. Am. Chem. Soc. 1956, 78, 4450-4452.

[15] R. A. Nugent, M. Murphy, S. T. Schlachter, C. J. Dunn, R. J. Smith, N. D. Staite, L. A. Galinet, S. K. Shields, D. G. Aspar, K. A. Richard, N. A. Rohloff, J. Med. Chem. 1993, 36, 134-139.

[16] P. C. B. Page, M. J. McKenzie, J. A. Galagher, J. Org. Chem. 2001, 66, 37043708.

[17] D. Simoni, N. Gebia, F. P. Invidiata, M. Eleopra, P. Marchetti, R. Rondanin, R. Baruchello, S. Provera, C. Marchioro, M. Tolomeo, L. Marinelli, V. Limongelli, E. Noveliono, A. Kwaasi, J. Dunford, S. Buccheri, N. Cacamo, F. Dieli, J. Med. Chem. 2008, 51, 6800-6807.

[18] D. Granchi, A. Scarso, G. Bianchini, A. Chiminazzo, A. Minto, P. Sgarbossa, R. A. Michelin, G. Di Pompo, S. Avnet, G. Strukul, Eur. J. Med. Chem. 2013, $65,448-455$.

[19] A. Chiminazzo, L. Sperni, M. Damuzzo, G. Strukul, A. Scarso, ChemCatChem 2014, 6, 2712-2718.

[20] G. Bianchini, A. Scarso, A. Chiminazzo, L. Sperni, G. Strukul, Green Chem. 2013, 15, 656-662.

[21] M. Ferrer-Casal, A. P. Barboza, S. H. Szajnman, J. B. Rodriguez, Synthesis 2013, 45, 2397-2404.

[22] R. Ruziconi, G. Rici, A. Gioiello, H. Couthon-Gourvès, J.-P. Gourvès, J. Org. Chem. 2003, 68, 736-742.

[23] O. Bortolini, I. Mulani, A. De Nino, L. Maiuolo, M. Nardi, B. Russo, S. Avnet, Tetrahedron 2011, 67, 5635-5641.

[24] Y. Guo, F. Chen, Chem. Abstr. 1986, 17, 8.

[25] N. Ischia, A. Palumbo, G. Prota, Tetrahedron 1988, 44, 6441-6466.

[26] J. F. M. Da Sila, S. J. Garden, A. C. Pinto, J. Braz. Chem. Soc. 2001, 12, 273324.

[27] a) M. S. Majik, C. Rodrigues, S. Mascarenhas, L. D'Souza, Bioorg. Chem. 2014, 54, 89-95; b) H. M. Zhang, H. Dai, P. J. Hanson, H. Li, H. Guo, X. Ye, M. G. Hemida, L. Wang, Y. Tong, Y. Qiu, S. Liu, F. Wang, F. Song, Z. Buchang, J.-G. Wang, L.-X. Zhang, D. Yang, ACS Chem. Biol. 2014, 9, 1015-1024; c) M. Kidwai, A. Jain, V. Nemaysh, R. Kumar, P.M. Luthra, Med. Chem. Res. 2013, 22, 2717-2723.

[28] S. N. Pandeya, P. Yogeeswari, D. Sriram, E. De-Clercq, C. Pannecouque, M. Wivrouw, Chemotherapy, 1999, 45, 192-196.

[29] S. N. Pandeya, D. Sriram, Acta Pharm. Turc. 1998, 40, 33-38.

[30] S. N. Pandeya, D. Sriram, G. Nath, E. De-Clercq, Indian J. Pharm. Sci. 1999, $61,358-361$.

[31] R. S. Varma, W. L. Nobles, J. Med. Chem. 1967, 10, 972-974.

[32] a) N. Lashgari, G. M. Ziarani, ARKIVOC 2012, (i) 277-320; b) N. R. BallJones, J. J. Badillo, A. K. Franz, Org. Biomol. Chem. 2012, 10, 5165-5181; c) S. Mohammadi, R. Heiran, R. P. Herrera, E. Marqués-López, ChemCatChem 2013, 5, 2131-2148.

[33] M. Flores, J. Pena, P. García-García, N. M. Garrido, D. Diez, Curr. Org. Chem. 2013, 17, 1957-1985.

[34] M. M. M. Santos, Tetrahedron 2014, 70, 9735-9757.

[35] a) M. M. Heravi, S. Asadi, Tetrahedron: Asymmetry 2012, 23, 1431-1465; b) Y. Liu, P. Gao, J. Wang, Q. Sun, Z. Ge, R. Li, Synlett 2012, 23, 1031-1034.

[36] a) T. Itoh, H. Ishikawa, Y. Hayashi, Org. Lett. 2009, 11, 3854-3857; b) G. Angelici, R. J. Corrêa, S. J. Garden, C. Tomasini, Tetrahedron Lett. 2009, 50, 814-817.

[37] L. Li, S. Gou, F. Liu, Tetrahedron: Asymmetry 2014, 25, 193-197.

[38] A. V. Malkov, M. A. Kabeshov, M. Bella, O. Kysilka, D. A. Malyshev, K. Pluháčková, P. Kočovský, Org. Lett. 2007, 9, 5473-5476. 
[39] Q. Guo, J. C.-G. Zhao, Tetrahedron Lett. 2012, 53, 1768-1771.

[40] S. Abbarajua, J. C.-G. Zhao, Adv. Synth. Catal. 2014, 356, 237-241.

[41] Y. Lu, Y. Ma, S. Yang, M. Ma, H. Chu, C. Song, Tetrahedron: Asymmetry 2013, 24, 1082-1088.

[42] a) T. Ohnuma, H. Kasuya, Y. Kimura, Y. Ban, Heterocycles 1982, 17, 377380; b) J. Frederick, D. Carlo, H. G. Lindwall, J. Am. Chem. Soc. 1945, 67, 199-201; c) G. Imanzadeh, T. Aghaalizadeh, M. Zamanloo, Y. Mansoori, J. Chil. Chem. Soc. 2011, 56, 616-620.

[43] Y. Xi, X. Shi, Chem. Commun. 2013, 49, 8583-8585.
[44] G. Luppi, P. Cozzi, B. Kaptein, Q. B. Broxterman, C. Tomasini. J. Org Chem. 2005, 70, 7418-7421.

[45] a) T. Marcelli, J. H. van Maarseveen, H. Hiemstra, Angew. Chem. Int. Ed. 2006, 45, 7496-7504; b) C. Ó Dálaigh, Synlett 2005, 5, 875-876.

[46] G. Qunsheng, B. Mayur, Z. Cong-Gui, Angew. Chem. Int. Ed. 2010, 49, 9460-9464.

Submitted: March 27, 2017

Accepted: March 31, 2017 